\title{
PLUME DISPERSION STUDY IN A INDUSTRIAL COMPLEX
}

\author{
VIDAL, César Marcelo Cajazeira, CORRÊA, Sérgio Machado \\ Universidade do Estado do Rio de Janeiro, Faculdade de Tecnologia, Departamento de Química e Ambiental, \\ Rod. Presidente Dutra km 298, Pólo Industrial, Resende, RJ, Brasil, 27537-000 \\ sergiomc@uerj.br
}

Received 13 December 2010; received in revised form 22 December 2010; accepted 28 December 2010

\section{RESUMO}

A modelagem de dispersão de plumas é usada para estimar a distribuição dos poluentes nas vizinhanças das chaminés. É baseado no modelo Gaussiano, onde os dados de entrada são as taxas de emissão, dados físicos da chaminé, dados meteorológicos e topográficos. Como é uma técnica recente no Brasil, este trabalho descreve a metodologia e seus passos, indicando os parâmetros mais relevantes, as possíveis simplificações e detalhamentos necessários. O estudo de caso foi realizado nas Indústrias Nucleares do Brasil, e os resultados indicaram que as edificações são o parâmetro mais importante, seguido da topografia. Uma comparação foi realizada entre dois softwares comerciais, o SCREEN e o ISCST3. Os resultados indicam que o SCREEN pode ser usado como uma ferramenta de avaliação inicial, quando nem todos os dados de entrada para processar o ISCST3 estão disponíveis.

Palavras-chave: plumas, dispersão, modelagem

\begin{abstract}
The plume dispersion modeling is used to estimate the pollutants distribution in the vicinities of a chimney. It is based on a Gaussian model where input data are the emissions rate, physical data from the stack, meteorological data, and topographical characteristics. As this technique is new in Brazil, this work proposes to describe the methodology and its steps, indicating the most relevant parameters, the possible simplifications, and necessary details. The case study was done at the site of Brazilian Nuclear Industries and the results indicated that the edifications are the most relevant parameter, followed by the topographical characteristics. A comparison was also done between the two commercial softwares available, the ISCST3 and SCREEN. The results indicated that the SCREEN software can be used as an initial evaluation tool, whenever all input data necessary to process ISCST3 are not available.
\end{abstract}

Keywords: plume, dispersion, modelling 


\section{Introdução}

A poluição do ar causada pela emissão de fontes fixas (chaminés) pode resultar em problemas que variam desde os arredores até quilômetros de distância. $O$ controle das emissões requer uma avaliação dos poluentes nos níveis qualitativo e quantitativo. Para estimar os impactos da emissão dos poluentes e a aplicabilidade de medidas de controle é preciso o uso de ferramentas matemáticas e dados experimentais. Um dos métodos utilizados é o cálculo de dispersão de plumas atmosféricas, que pode prever com quais concentrações os poluentes emitidos por uma chaminé irão atingir o nível do solo e em que localidade será atingida a concentração máxima, assim como as suas vizinhanças.

Existem diversos modelos para o cálculo de dispersão de plumas atmosféricas. Com base no algoritmo de cálculo, existem os modelos Gaussianos, Numéricos, Estatísticos e Físicos, sendo os Gaussianos mais empregados por sua simplicidade, por já terem sido testados exaustivamente e por serem de ampla aceitação pelas agências ambientais.

No modelo apresentado neste estudo, o algoritmo de cálculo empregado é integrante dos softwares SCREEN e ISCST3, de livre distribuição, pela Agência de Proteção Ambiental Norte Americana (US-EPA). O algoritmo usado pelo software SCREEN baseia-se em um cálculo gaussiano de uma fonte fixa, podendo ser estendido para múltiplas fontes de acordo com uma metodologia para agrupamento de fontes. $O$ cálculo também pode ser efetuado para fontes de áreas como emissões de aterros ou incêndios e de fontes volumétricas como um bloco. Já o software ISCST3, também da US-EPA, é empregado para avaliações de fontes individuais múltiplas e de grande complexidade, como múltiplos prédios e terrenos assimétricos como é o caso de uma refinaria (Vidal, 2008).

Vários são os parâmetros que devem ser monitorados e requeridos para o cálculo de dispersão de plumas atmosféricas, portanto, as informações sobre fonte de emissão, meteorologia, poluentes, edificações e topografia merecem destaque.

Com base nas informações das condições de contorno, é possível realizar uma simulação através do cálculo de dispersão de plumas para a avaliação dos poluentes emitidos para a atmosfera.
Este trabalho se propõe a descrever a metodologia de abordagem para decisão de escolha dos softwares (SCREEN e ISCST3) a ser empregado no cálculo de dispersão de plumas atmosféricas, ou seja, decidir sobre quais simplificações podem ser feitas e quais detalhamentos não podem ser desprezados.

Para entendimento da equação geral de plumas gaussianas, foi levado em consideração o desenvolvimento da expressão Lagrangiana básica para concentração média de um poluente no tempo e no espaço, segundo a Equação 1.

O primeiro termo do lado direito representa as partículas presentes em $t_{0}$, e o segundo termo do lado direito se refere às partículas acrescentadas das fontes entre $t_{0}$ e $t$.

A Equação 1 é a relação Lagrangiana fundamental para a concentração média de uma espécie em fluxo turbulento. A determinação de $\langle c(\boldsymbol{x}, t)\rangle$, dado que $\left\langle c\left(\boldsymbol{x}_{0}, t_{0}\right)\right\rangle$ e $\mathrm{S}\left(\boldsymbol{x}^{\prime}, t\right)$, depende da avaliação da probabilidade de transição $Q\left(x, t \mid x^{\prime}\right.$, $\left.t^{\prime}\right)$. Se $Q$ fosse conhecido por $x, x^{\prime}, t$, a concentração média $\langle c(\boldsymbol{x}, t)\rangle$ poderia ser computada simplesmente avaliando a Equação 1. No entanto, existem dois problemas substanciais ao se utilizar a Equação 1. Primeiramente, a equação se mantém apenas quando as partículas não sofrem reações químicas. Em segundo lugar, o conhecimento completo das propriedades da turbulência, necessário para se conhecer $Q$ geralmente não está disponível, exceto nas circunstâncias mais simples.

O cálculo envolvendo o modelo de pluma gaussiana possui uma aplicação mais prática e avalia a concentração dos poluentes emitidos por uma fonte fixa através da Equação 2.

A densidade de probabilidade de transição $Q$ expressa fisicamente a probabilidade de uma partícula traçadora, que está em x', y', z', num tempo $t^{\prime}$, estar em $x, y, z$, num tempo t. Sob condições estacionárias, a turbulência homogênea $Q$ tem a forma Gaussiana.

Nas condições usuais para se estimar o impacto de fontes estacionárias nas vizinhanças, algumas simplificações para as Equações 1 e 2 podem ser realizadas, como por exemplo:

- A estabilidade da atmosfera é uniforme na região de estudo;

- A diluição vertical e horizontal pode ser descrita por uma curva gaussiana; 
- A liberação dos poluentes é feita a uma altura equivalente a altura da chaminé mais a elevação da pluma;

- O grau de diluição do poluente é inversamente proporcional a velocidade do vento;

- O poluente ao atingir o solo é refletido de volta para a atmosfera, não sofrendo interação;

- Não há reação química entre as espécies emitidas nem entre estas e os demais constituintes da atmosfera em estudo.

Empregando-se estas simplificações as Equações 1 e 2 podem ser reduzidas a Equação 3.

Onde:

$c=$ Concentração do poluente nas coordenadas em $x, y e z, g^{-3}$

$x=$ distância horizontal da emissão ao receptor (m)

$y=$ distância horizontal do ponto de medição a uma distância $y$ da linha central da pluma $(\mathrm{m})$

$z=$ altura do receptor $(\mathrm{m})$

$q$ = taxa de emissão do poluente $\left(\mathrm{g} \mathrm{s}^{-1}\right)$

$\sigma_{y}, \sigma_{z}=$ Coeficientes de dispersão vertical e horizontal $(\mathrm{m})$

$u=$ velocidade média do vento na altura da chaminé $\left(\mathrm{m} \mathrm{s}^{-1}\right)$

$h=$ Altura efetiva de lançamento $(\mathrm{m})$

As correlações $\sigma_{y}$ e $\sigma_{z}$, mais amplamente usadas, com base nas classes de estabilidade de Pasquill, foram àquelas desenvolvidas por Gifford (Seinfeld e Pandis, 1998). Significam a abertura da pluma conforme se afasta da fonte, é fortemente dependente da estabilidade da atmosfera, que é função dos ventos que irão transportar a pluma horizontalmente e a radiação solar que irá ampliar a pluma verticalmente ao solo. A estabilidade da atmosfera é amplamente aceita pela proposta de Pasquill-Gifford está apresentada na Tabela 1.

A estabilidade da atmosfera pode ser definida como sendo a sua capacidade de resistir ou intensificar os movimentos verticais. Quando ela resiste aos movimentos verticais é chamada de atmosfera estável, quando intensifica os movimentos verticais é dita atmosfera instável ou convectiva, e quando é indiferente a qualquer tipo de movimento vertical é chamada atmosfera neutra. Através do perfil de temperatura potencial $(\theta)$ na vertical, pode-se determinar o grau de estabilidade da atmosfera, e cada tipo de estabilidade atmosférica irá proporcionar uma melhor ou pior dispersão dos poluentes. A temperatura potencial pode ser definida como a temperatura que uma parcela de ar teria, se fosse trazida adiabaticamente de um determinado nível até o nível de 1000 mbar. O conceito de temperatura potencial está intimamente relacionado com o conceito de estabilidade estática, ou seja, um arranjo do fluido em que a porção mais leve fica acima da porção mais pesada. Assim, de duas parcelas $\operatorname{com} \theta$ diferentes, aquela com maior $\theta$ será a mais leve (Moreira e Tirabassi, 2004).

Portanto, o perfil vertical de temperatura próximo ao solo é um dos fatores que mais influenciam a dispersão dos poluentes na atmosfera, até mais importante que a intensidade dos ventos. Condições neutras são caracterizadas pela ocorrência de um perfil vertical de temperatura adiabático (aproximadamente constante com a altura). Essas condições ocorrem geralmente durante as transições do dia para noite e vice-versa, em dias nublados, ou com fortes ventos (com velocidades maiores do que $6 \mathrm{~m} \mathrm{~s}^{-1}$ ).

Os parâmetros meteorológicos são fundamentais para a dispersão dos poluentes. É um fator primário que determina o efeito de diluição da atmosfera. Normalmente, é necessário o levantamento da distribuição conjunta de classes de velocidade dos ventos e categorias de estabilidade atmosféricas para as diversas direções do vento. Essa matriz é utilizada como dado de entrada de diversos modelos (Derisio, 2000).

O movimento dos poluentes na atmosfera é determinado pelos seguintes fatores:

- Turbulência mecânica provocada pelo vento na instabilidade direcional e de velocidade;

- Turbulência térmica resultante de parcelas de ar superaquecido que ascendem da superfície terrestre, sendo substituídas pelo ar mais frio em sentido descendente;

- Topografia da região.

A concentração resultante na atmosfera varia de acordo com o ponto no espaço em consideração, a quantidade e as condições de emissão e nos fatores citados anteriormente, 
somados aos fatores de chuva e condições de inversão térmica. Resumindo, a concentração do poluente na atmosfera é função da quantidade e das condições de emissão, das condições meteorológicas e da topografia (Uehara, 2003).

Moreira \& Tirabassi (2004) descrevem que a gestão e a proteção da qualidade do ar pressupõem o conhecimento do estado do ambiente. Tal conhecimento envolve um aspecto propriamente cognitivo e um interpretativo. A rede de pesquisa, juntamente com o inventário das fontes de emissão, é de fundamental importância para a construção do quadro cognitivo, mas não do interpretativo. $\mathrm{Na}$ realidade, o controle da qualidade do ar requer instrumento interpretativo capaz de extrapolar no espaço e no tempo os valores medidos na posição dos analisadores. Enquanto a melhoria da atmosfera pode ser obtida somente com planos que reduzam as emissões e, então, com instrumentos (como o modelo matemático de dispersão na atmosfera) capazes de ligar a causa (a fonte) de poluição com o efeito (a concentração. do poluente).

\section{Parte Experimental}

\section{Modelo ISCST3}

O modelo de dispersão ISCST3 (USEPA, 1995) (Industrial Source Complex - Short Term Version 3) é um modelo de pluma Gaussiana de estado estacionário que pode ser utilizado na avaliação de concentrações de poluentes e/ou nos fluxos de deposição a partir de uma grande variedade de fontes associadas a uma fonte industrial complexa.

Nos Estados Unidos, o ISCST3 foi substituído pelo AERMOD; no Brasil, o mesmo ainda é recomendado especificamente com relação a estudos de qualidade do ar, e prognóstico da área de influência.

O modelo de dispersão ISCST3 da Agência de Meio Ambiente Norte Americana (EPA) foi projetado para suportar as opções de regulamentação dos modelos, conforme especificado nas diretrizes sobre os modelos de qualidade do ar. Algumas das habilidades da modelagem com o ISCST3 incluem:

- O modelo ISCST3 pode ser utilizado para modelar poluentes primários e emissões contínuas de poluentes tóxicos e perigosos;

- O modelo ISCST3 pode lidar com fontes múltiplas, incluindo os tipos ponto, volume, área e cavidades abertas. Fontes lineares também podem ser modeladas como fontes de corrente de volume ou áreas alongadas;

- As taxas de emissão das fontes podem ser tratadas como constantes ou podem variar por mês, estação, horário ou outros períodos opcionais, tanto para uma única fonte ou para um grupo de fontes;

- O modelo pode considerar os efeitos de downwash aerodinâmicos devido à proximidade de edifícios com as emissões da fonte pontual;

- O modelo contém algoritmos para modelar os efeitos de deposição e remoção (através da deposição seca) de particulados grandes, bem como modelar os efeitos das remoções por precipitação para gases ou particulados;

- A localização de receptores pode ser especificada tanto em receptores em grade e/ou discretos, num sistema de coordenadas polares ou cartesianos;

- O ISCST3 incorpora os algoritmos de modelos de visualização de dispersão COMPLEX 1 para receptores em terrenos complexos.

- O modelo ISCTS3 utiliza dados meteorológicos em tempo real para considerar as condições atmosféricas que afetam a distribuição dos impactos da poluição do ar na área modelada;

- Resultados de saída (output) para Concentração, deposição total, e fluxo de deposição seca e/ou úmida.

Segundo Negri (2002), o modelo ISCST3 permite associar cenários climáticos próximos da realidade física, sendo utilizado tanto pela comunidade acadêmica como pelas agências nacionais e internacionais de controle ambiental. O cálculo de concentração de poluentes permite a obtenção de resultados nas escalas espacial e temporal, os quais são comparados posteriormente aos padrões vigentes no país (CONAMA, 1990). O modelo aceita dados de entrada de mais de 500 fontes simultâneas tipo pontual e área e gera cerca de mais de 1.500 
receptores na superfície. Os receptores são distribuídos dentro de uma grade cartesiana, cujas quadrículas aceitam áreas variáveis. Esse modelo permite incorporação das fontes pontuais equivalentes e as fontes áreas estabelecidas para as fontes móveis (veiculares) e agrícolas (queima de cana), por exemplo.

\section{Modelo SCREEN}

De acordo com a USEPA, o modelo SCREEN3 (USEPA, 1995) foi desenvolvido para fornecer um método de simples manuseio para a obtenção de estimativas da concentração de poluentes. Essas estimativas se baseiam no documento "Procedimentos de Visualização para Estimativas do Impacto da Qualidade do Ar de Fontes Estacionarias".

A versão SCREEN3 3.0 do modelo SCREEN pode fornecer todos os cálculos em curto prazo de uma única fonte, no documento de procedimentos de visualização da EPA, incluindo:

- Estimativa de concentrações máximas ao nível do solo e a distância até o valor máximo;

- Incorporação dos efeitos de "building downwash" nas concentrações máximas tanto nas laterais próximas como nas mais distantes regiões;

- Estimativa de concentrações na zona de recirculação de cavidade;

- Estimativa de concentrações devido à quebra de inversão e fumigação no litoral;

- Determinação da elevação da pluma para liberação dos gases de queimadores;

- Incorporação dos efeitos da simples elevação do terreno nas concentrações máximas;

- Estimativa de concentrações médias de 24 horas devido ao impacto da pluma em terreno complexo, por meio da utilização do procedimento de visualização de 24 horas, usando o modelo VALLEY;

- Modelagem de fontes de área simples utilizando uma abordagem de integração numérica;

- Pode ser usado para modelagem dos efeitos de fontes de volume simples usando um procedimento de fonte pontual virtual;

- Cálculo da Concentração máxima, a qualquer distância especificada pelo usuário em terreno plano ou elevado simples, incluindo distâncias até 100 km para transportes de longo alcance.

- Exame de uma ampla faixa de condições meteorológicas, incluindo todos os tipos de classes de estabilidade e velocidade eólica para calcular os impactos máximos;

- Inclusão dos efeitos da dispersão induzida pela força ascencional (buoyancy-induced dispersion (BID);

- Cálculo explícito dos efeitos de reflexões múltiplas da pluma tanto fora da inversão elevada como acima do solo;

- Quando calcula concentrações abaixo das condições limites da mistura;

O modelo SCREEN3 não será capaz de realizar o seguinte:

- Determinar explicitamente os impactos máximos a partir de múltiplas fontes, excetuando-se os procedimentos de manipulação de múltiplas fontes próximas, pela fusão das emissões em uma única chaminé "representativa".

Nota: À exceção da estimativa de 24 horas para impactos em terrenos complexos, os resultados do SCREEN3 são estimados para concentrações máximas de 1 hora.

O modelo SCREEN foi desenvolvido para se obter a concentração de poluentes no nível do solo em regiões onde não existam dados meteorológicos disponíveis. Portanto, é de grande utilidade para a estimativa da concentração de poluentes em regiões carentes de informações. Apresenta resultados de concentração de poluentes superestimados, vinculados à classe de estabilidade atmosférica mais crítica. Contudo, no caso de disponibilidade de dados meteorológicos locais, o modelo SCREEN possibilita diretamente a entrada dessas informações. Tem como principal limitação a incorporação de apenas uma fonte pontual, não tendo a representação de fontes tipo área. Neste caso, as fontes móveis e agrícolas devem ser distribuídas na área típica.

Com o advento e multiplicação dos computadores pessoais, muitos modelos foram desenvolvidos utilizando os métodos de 
diferenças finitas ou métodos de elementos finitos.

Os modelos são desenvolvidos em parceria com Universidades e Instituições de Pesquisas Atmosféricas na linguagem de programação Fortran e divulgados no sistema Disk Operating System (DOS). Todos os modelos da USEPA são gratuitos e disponibilizados em seu site, após vários testes de laboratório, campo e computacional. Não estão disponibilizados para o sistema operacional Windows.

À medida que uma empresa se interessa em comercializar um modelo com interface gráfica para o sistema operacional Windows, é necessário que haja autorização da USEPA, porque ela é detentora dos direitos do programa fonte. A interface gráfica possibilita a utilização integrada, linguagem acessível, fácil entrada e modificação de dados, assim como visualização gráfica dos resultados.

\section{Dados de Entrada dos Modelos}

Os dados de entrada para o processamento do modelo foram cedidos pelas Indústrias Nucleares do Brasil (INB), Resende RJ.

O levantamento topográfico, em torno da INB cujo raio foi de $1,7 \mathrm{~km}$, a partir da base de cartas topográficas digitais terrestres da Missão SRTM - Shuttle Radar Topography Mission (2007). Embora esse raio seja inferior a área de influência da empresa, os resultados obtidos evidenciaram valores baixos no limite desta área.

As informações das edificações (altura, comprimento e largura) e das chaminés (diâmetro, altura, taxa de emissão, velocidade e temperatura de saída dos gases), Tabela 2, foram disponibilizadas através dos desenhos de projeto e relatório de amostragem das chaminés.

Foi pré-processado um arquivo meteorológico para uso no ISCST3 com base de dados meteorológicos médios horários coletados pela torre meteorológica, no período de 2006, conforme apresentado na Tabela 2.

\section{Descrição do local de estudo}

Abrangendo um raio de até $4 \mathrm{~km}$ do local de instalação da INB no município de Resende, a Área de Interesse Especial contempla cerca de 5 unidades rurais fronteiriças ao imóvel, incluindo 2 hotéis na localidade de Engenheiro Passos e respectiva vila da COHAB (Resende). O município de Resende, com área de $1.155 \mathrm{~km}^{2}$, limita-se ao Norte com o Estado de Minas Gerais, ao Sul e a Oeste com o Estado de São Paulo. Nesta região, o tráfego de veículos na Rodovia Presidente Dutra (BR-116) apresenta um fluxo diário de aproximadamente 145.000 veículos pedagiados, dos quais $57 \%$ veículos de passeio e $43 \%$ caminhões e ônibus. Itatiaia, antigo distrito de Resende, com área de $248 \mathrm{~km}^{2}$, limita-se ao Norte com Minas Gerais, ao Sul com São Paulo, a Leste com Resende e a Oeste com Minas Gerais e São Paulo. No Vale do Paraíba Paulista, o município de Queluz, com $243 \mathrm{~km}^{2}$, limita-se a Oeste com o Estado do Rio de Janeiro (Resende) e ao Norte com Minas Gerais. Com $316 \mathrm{~km}^{2}$, o município de Areias limita-se com o Estado do Rio de Janeiro (Resende) e Queluz ao Norte, com Silveiras a Leste, a Oeste com São José do Barreiro e ao Sul com Cunha. O município de São José do Barreiro, com 710 km², limita-se ao Norte com o município de Resende (RJ), a Leste com Bananal (SP), ao Sul com Cunha, a Oeste com Areias (SP) e a Sudeste com Paraty e Angra dos Reis (INB, 1998).

A partir da caracterização técnica preliminar do empreendimento, a área de influência está definida em dois níveis: uma área de influência indireta que cobre os municípios de Resende, Itatiaia, São José do Barreiro, Areias e Queluz, analisada do ponto de vista geobiofísico em escala 1:100.000 e no contexto ecológico e sócio-econômico da região do médio Paraíba; e uma área de influência direta, ou área de interesse especial, definida como o entorno imediato do empreendimento nos municípios de Itatiaia, Resende e Queluz, analisada em escalas de 1:50.000 e mais e objeto de pesquisas diretas de campo (INB, 1998).

A topografia influencia a dispersão dos poluentes por ocasionar variação na direção/velocidade do vento.

A área da INB possui, na sua parte leste, uma topografia essencialmente pouco acidentada, constituída por terrenos aplainados, em virtude de terem sido utilizados como áreas de empréstimo, quando da construção da barragem auxiliar de Nhangapi da represa do Funil. $\mathrm{Na}$ sua porção leste e sul, a área apresenta uma topografia ondulada, com altitudes variando de 450 a pouco mais de 600 m. A porção extremo leste da área está numa 
cota inferior a da crista da barragem, que é de 469,5 m.

O local está situado na parte meridional da região geologicamente denominada Bacia de Resende. Ao norte, situa-se o maciço do Itatiaia, que constitui as grandes altitudes da região, atingindo cotas superiores a $2.500 \mathrm{~m}$. Ao sul, ocorre uma faixa acidentada de terreno, com altitudes máximas variando entre 530 e $615 \mathrm{~m}$.

\section{Meteorologia}

A partir dos eventos médios horários analisados e considerados válidos no período do ano de 2006 (total de 8760 horas), originam-se a rosa-dos-ventos observada no sítio da INB no período de 2006, analisado por velocidade do vento e classe de estabilidade, respectivamente, segundo a Figura 1.

\section{Resultados e Conclusões}

Com o objetivo de estimar concentrações de particulados totais em suspensão, levando em consideração dados de topografia e edificações no processamento do cálculo de dispersão de plumas em um tempo de exposição de 1 hora (cenário mais crítico - Caso Base) para emissão das chaminés da Fábrica de Pó e Pastilha (FPP) e Secador Spray (SS), foram processados no ISCST3 as médias aritméticas das concentrações horárias (isoconcentrações ou isopletas) deste período com diferentes cenários apresentados nas Figuras 2, 3, 4 e 5.

A Figura 2 apresenta os resultados levando-se em consideração a influência das edificações, relevo e das duas chaminés em estudo, para material particulado, com resultados mais conservadores de 1 hora.

A Figura 3 apresenta os resultados do processamento levando em consideração a presença das edificações e a ausência da topografia.

Os perfis das concentrações, do processamento com a ausência da topografia e presença das edificações, indicaram circulações locais em torno dos prédios o que propicia o aumento das concentrações em áreas mais próximas dos prédios.

A Figura 4 apresenta os resultados do processamento levando em consideração a ausência das edificações e a presença da topografia.

A Figura 5 apresenta os resultados do processamento levando em consideração a ausência das edificações e da topografia.

A distribuição da concentração, do processamento com a ausência da topografia e das edificações, está diretamente condicionada à distribuição do campo de ventos em torno da INB.

Também foram processados os cálculos removendo-se a chaminé da FPP e do SS alternadamente para verificar a influência de cada fonte isoladamente. Com base nos resultados de concentração máxima da Tabela 3 , a concentração integrada das chaminés é resultante da superposição das duas plumas a uma determinada distância das chaminés. No entanto, isso não representa o somatório da concentração das duas chaminés.

Os resultados evidenciam que o relevo e principalmente os prédios influenciam diretamente no aumento da concentração. Conseqüentemente, a ausência do relevo e em especial dos prédios evidenciam a redução da concentração. A distância de deposição da concentração máxima ratifica que o relevo e preponderante os prédios influenciam na distância de deposição do poluente próximo as instalações.

No cenário sem relevo e com prédios, observa-se também, que os prédios influenciam na distância de deposição do efluente gasoso do Secador Spray, depositando-se próximo da fonte devido a direção predominante do vento na saída da chaminé e de encontro com os prédios da fábrica de Pó e Pastilha.

Os demais cenários confirmam que a distância de deposição da concentração de máxima da chaminé da fábrica de Pó e Pastilha é menor que a do Secador Spray, sendo a vazão de saída dos gases, o principal fator que contribui para esse acontecimento.

A concentração máxima está diretamente proporcional a configuração da fonte e observase também que os prédios não influenciam na concentração máxima do efluente da fábrica de Pó e Pastilha.

A distância onde é observada a concentração máxima é inversamente proporcional à própria concentração. Ou seja, quanto maior a distância que a pluma percorre, maior será seu espalhamento nas direções y e z 
(vertical e horizontal), e com isso os poluentes serão diluídos. Conclui-se que um estudo preliminar antes da implantação de um empreendimento, que fará uso de uma chaminé para a dispersão de poluentes, é de grande importância. Este estudo possibilitará indicar que, na direção predominante do vento, não deve haver obstáculos, como edificações e relevo acidentado, para a pluma poder percorrer um caminho livre e não formar regiões de estagnações, possibilitando assim a diluição dos poluentes.

Levando em consideração o cenário completo de emissões, foram avaliados cenários para períodos de exposição 1, 3, 12, 24 horas e anual. Consequentemente, quanto maior o período menor é a concentração, por isso o período de 1 hora é o caso mais crítico e deve ser levado em consideração em estudos de impacto ambiental. Estes resultados estão apresentados na Tabela 4.

O ISCST3 é um software de alta complexidade, para sua utilização, muitos dados são necessários e nem sempre estão disponíveis, requer treinamento adequado e algumas simplificações podem ser feitas pelo o uso do software SCREEN.

A comparação entre os softwares (ISCST3 e SCREEN), foi realizada indicando se realmente existe a possibilidade de substituir 0 ISCST3 pelo SCREEN. Foi realizado o processamento do SCREEN, com base no cenário que evidenciou melhor similaridade (sem relevo e sem edificações).

O processamento no SCREEN, em função de sua limitação, foi realizado individualmente para cada chaminé.

Os resultados de concentração máxima de material particulado e distância de deposição são apresentados na Tabela 5 , confrontando os softwares ISCST3 e SCREEN.

As diferenças não são tão grandes quando se deixa de considerar as edificações e o relevo. O erro foi de 13,8 \% para concentração da chaminé da fábrica de pó e pastilha e 29,2\% para chaminé do secador spray.

Espereva-se que o resultado do SCREEN fosse realmente maior devido sua característica mais conservativa em relação ao ISCST3. No entanto, menos preciso comparado ao ISCST3, pois o mesmo é um modelo mais sofisticado.

\section{Conclusões}

O cálculo de dispersão de plumas atmosféricas a partir de modelos gaussianos é um instrumento de estudo simplificado da realidade e passível de uma série de críticas, segundo os pontos de vista teórico e de aplicação prática. Todavia, tal modelo tem sido aceito como uma 'ferramenta de trabalho' em estudos de avaliação para a emissão de fontes fixas, pois serve para ilustrar comparativamente diferentes cenários de emissão de poluentes. Além disso, não existe um ganho significativo de informação gerado pela aplicação de modelos mais sofisticados se não existirem dados adequados para o uso de tais modelos. Portanto, aplicação do modelo de 'pluma gaussiana' deve ser considerada em função dos objetivos da análise em questão, dos recursos disponíveis e das condições locais existentes.

No caso específico da INB, observou-se uma grande influencia das edificações e do relevo no resultado final dos cálculos, tanto no alcance da pluma como nas concentrações máximas obtidas.

Uma comparação entre o ISCST3 e o SCREEN indicou que é possível usar esta ferramenta simplificada para estimar os efeitos de uma fonte fixa na INB.

Neste trabalho não foram consideradas as influências dos corpos de água no entorno da INB, que certamente tem relativa influência no cálculo.

Por questão de sigilo, as taxas de emissões dos poluentes foram usadas parametrizadas, mas que não influenciam na forma da pluma e de seu alcance, bastando multiplicar a taxa de emissão pelo respectivo fator de correção e conseqüentemente as concentrações obtidas.

\section{Referências}

1. VIDAL, C. M. C.. Descrição da metodologia de calculo de dispersão de plumas aplicada a um complexo industrial. Rio de Janeiro: UERJ, 2008. Dissertação de Mestrado. Programa de Pós Graduação em Química, Universidade do Estado do Rio de Janeiro, 2008.

2. SEINFELD, J. H.; PANDIS, S.N.; Atmospheric Chemistry and Physics, USA: John Wiley \& Sons, 1998. 
3. Moreira, D.; Tirabassi, T.; Ambiente \& Sociedade 2004, 7(2), 159.

4. DERISIO, J. C.; Introdução ao Controle de Poluição Ambiental, 2. ed. São Paulo: Signus Editora, 2000.

5. UEHARA, S.; Revista Meio Ambiente Industrial 2003, 40, 36.

6. U.S. Environmental Protection Agency. User's guide for the industrial source complex (ISC3) dispersion models, volume ii Description of model algorithms. EPA-454/b95-003b, North Carolina 27711, 1995.

7. NEGRI, J. C., Tese de Doutorado, Universidade de São Paulo, Brasil, 2002.
8. CONAMA. Resolução 03 de 28 de junho 1990.

9. U.S. Environmental Protection Agency. SCREEN3 - Model user's guide. EPA-454/b95-004, North Carolina 27711, 1995.

10. Missão SRTM (shuttle radar topography mission). disponível em: http://seamless.usgs.gov/ acesso em out 2007;

11. INB, Estudo de Impacto Ambiental e Relatório de Impacto Ambiental, 1998.

$$
\begin{aligned}
& \langle c(x, t)\rangle=\int_{-\infty}^{\infty} \int_{-\infty}^{\infty} \int_{-\infty}^{\infty} Q\left(x, t \mid x_{0}, t_{0}\right)\left\langle c\left(x_{0}, t_{0}\right)\right\rangle d x_{0}+\int_{-\infty}^{\infty} \int_{-\infty}^{\infty} \int_{-\infty}^{\infty} \int_{t_{0}}^{t} Q\left(x, t \mid x^{\prime}, t^{\prime}\right) S\left(x^{\prime}, t^{\prime}\right) d t^{\prime} d x^{\prime} \\
& \langle c(x, y, z, t)\rangle=\int_{-\infty}^{\infty} \int_{-\infty}^{\infty} \int_{-\infty}^{\infty} Q\left(x, y, z, t \mid x_{0}, y_{0}, z_{0}, t_{0}\right)\left\langle c\left(x_{0}, y_{0}, z_{0}, t_{0}\right)\right\rangle x d x_{0} d y_{0} d z_{0}+\int_{-\infty}^{\infty} \int_{-\infty-\infty}^{\infty} \int_{t_{0}}^{\infty} \int_{t_{0}}^{t} Q\left(x, y, z, t \mid x^{\prime}, y^{\prime}, z^{\prime}, t^{\prime}\right) x S\left(x^{\prime}, y^{\prime}, z^{\prime}, t^{\prime}\right) d t^{\prime} d x^{\prime} d y^{\prime} d z^{\prime} \\
& \langle c(x, y, z)\rangle=\frac{q}{2 \pi \bar{u} \sigma_{y} \sigma_{z}} \exp \left(-\frac{y^{2}}{2 \sigma_{y}^{2}}\right) x\left[\exp \left(-\frac{(z-h)^{2}}{2 \sigma_{z}^{2}}\right)-\exp \left(-\frac{(z+h)^{2}}{2 \sigma_{z}^{2}}\right)\right]
\end{aligned}
$$

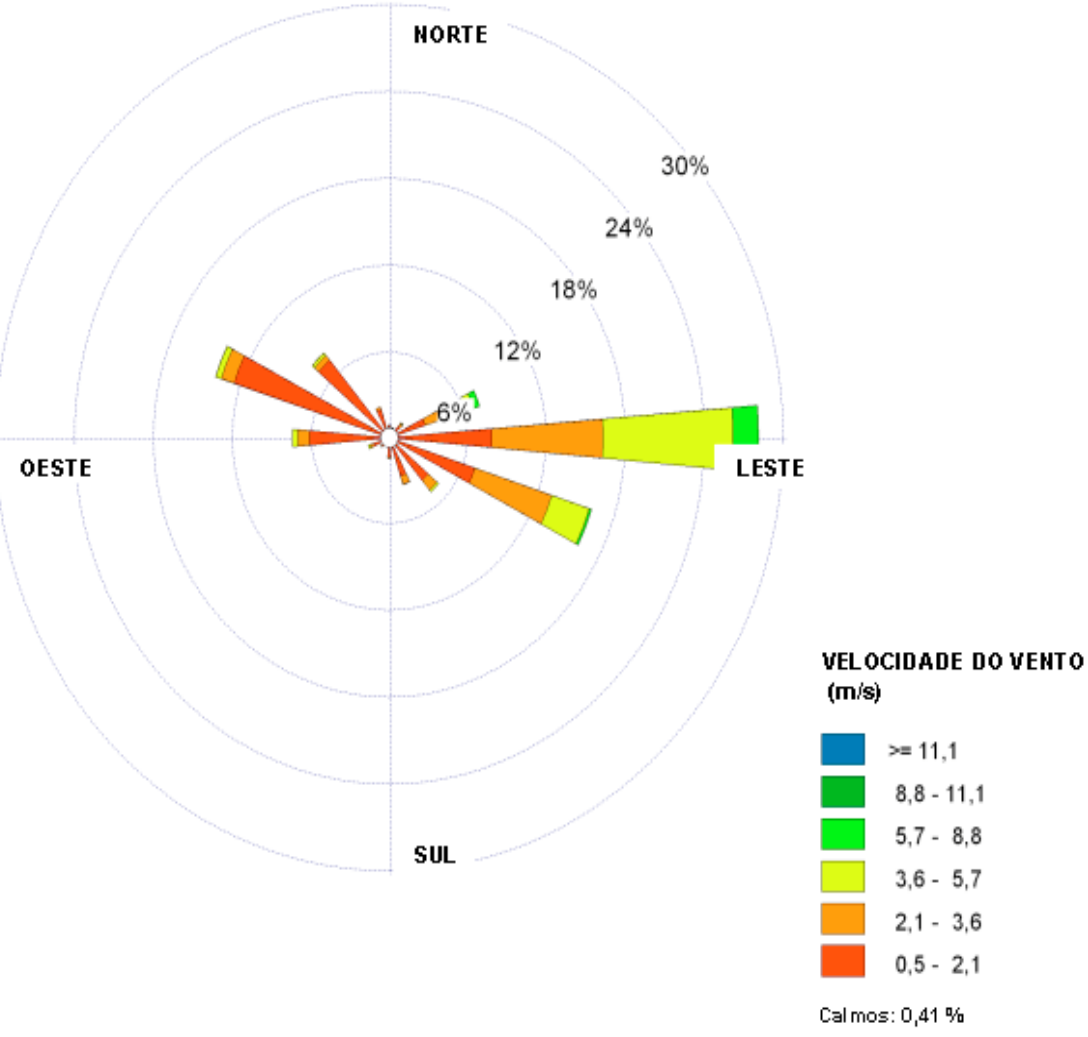

Figura 1 - Rosa dos ventos dos valores de 2006 obtidos pela estação meteorológica da INB. 


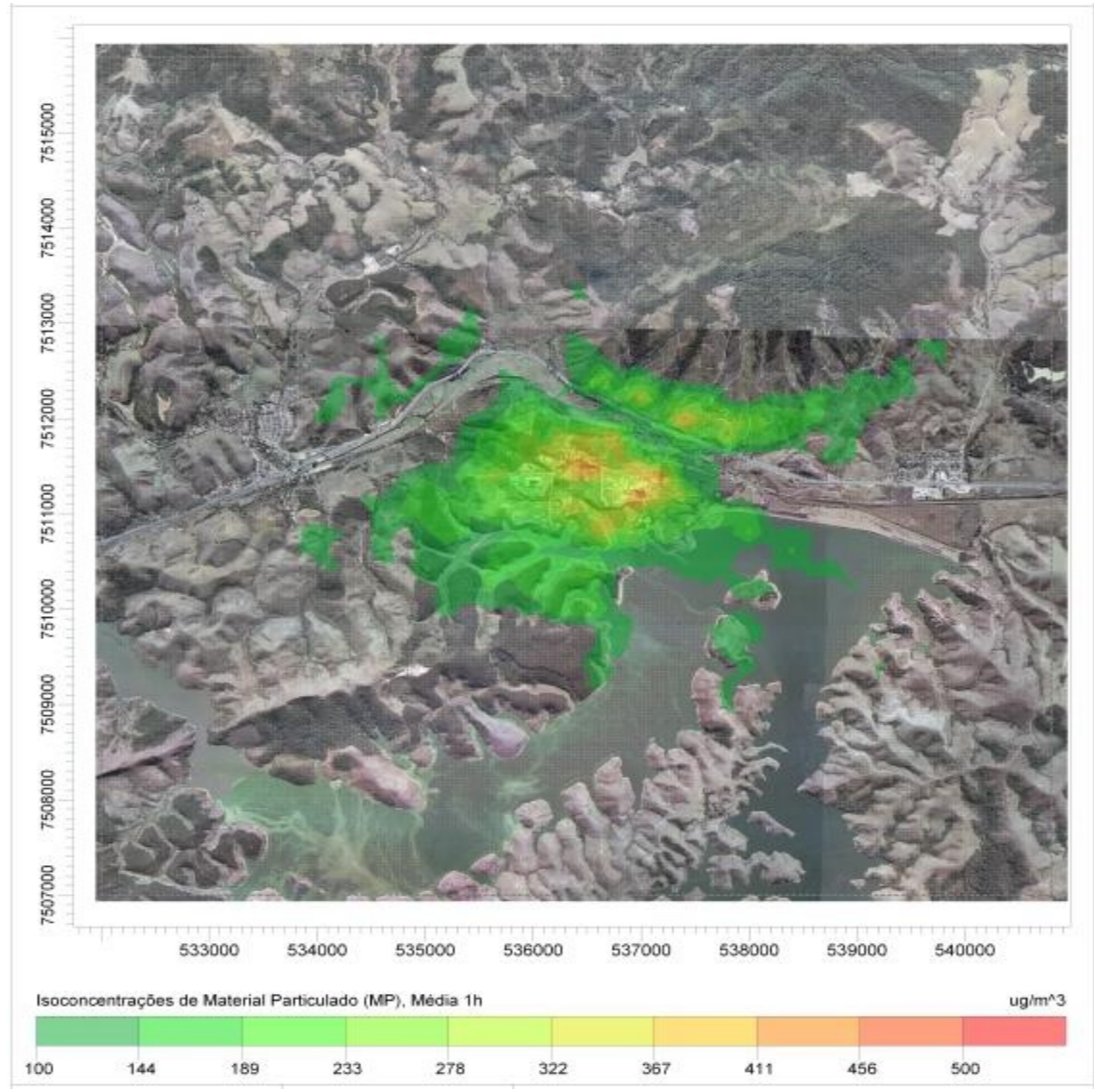

Figura 2 - Concentração Máxima de MP para as chaminés FPP e SS, 470,9 $\mu \mathrm{g} \mathrm{m}^{-3}$, Média 1 hora Caso Base

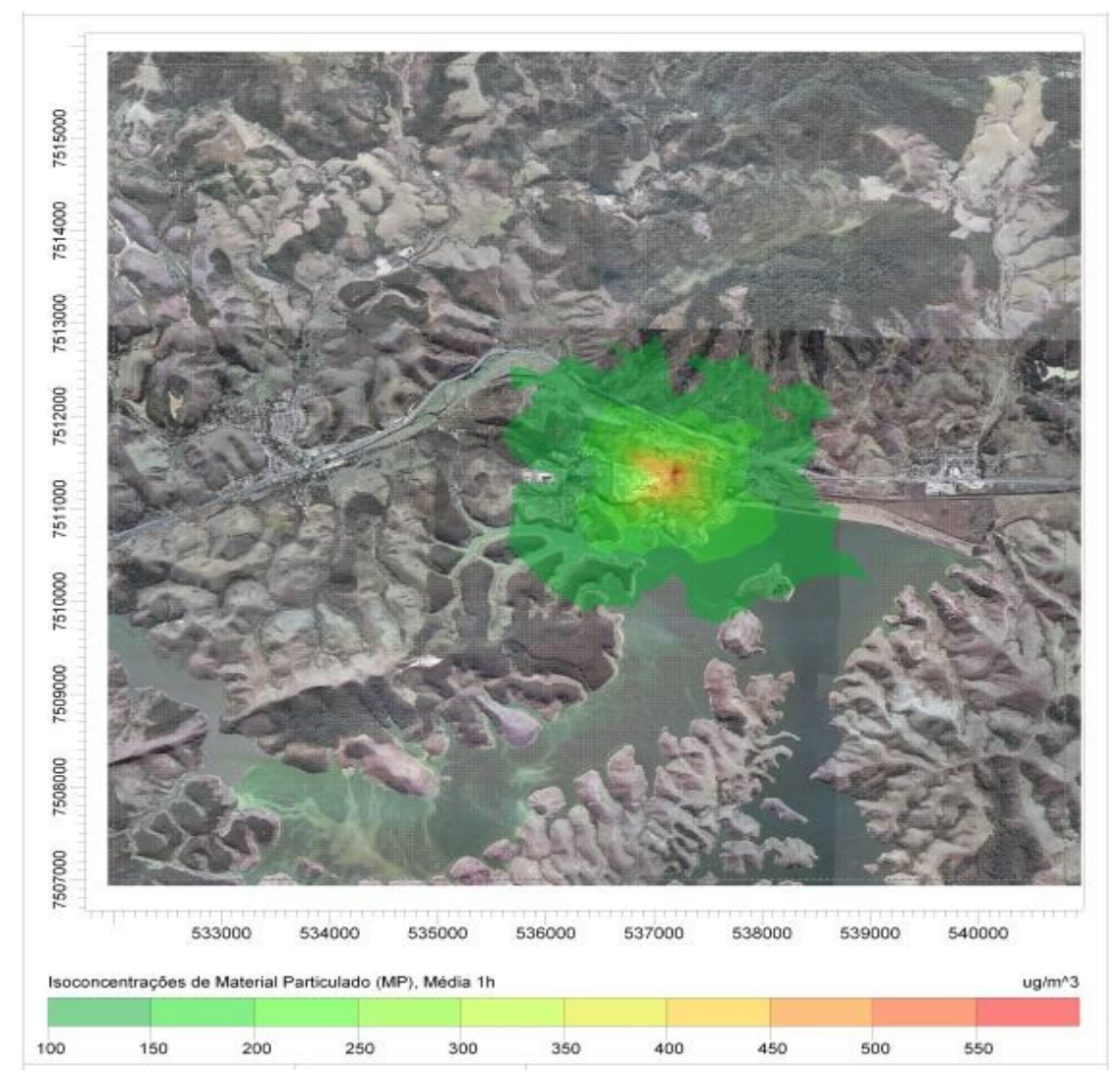

Figura 3 - Concentração. Máxima de MP para as chaminés FPP e SS, 537,7 $\mu \mathrm{g} \mathrm{m}^{-3}$, Média 1 hora (com edificações e sem relevo) 


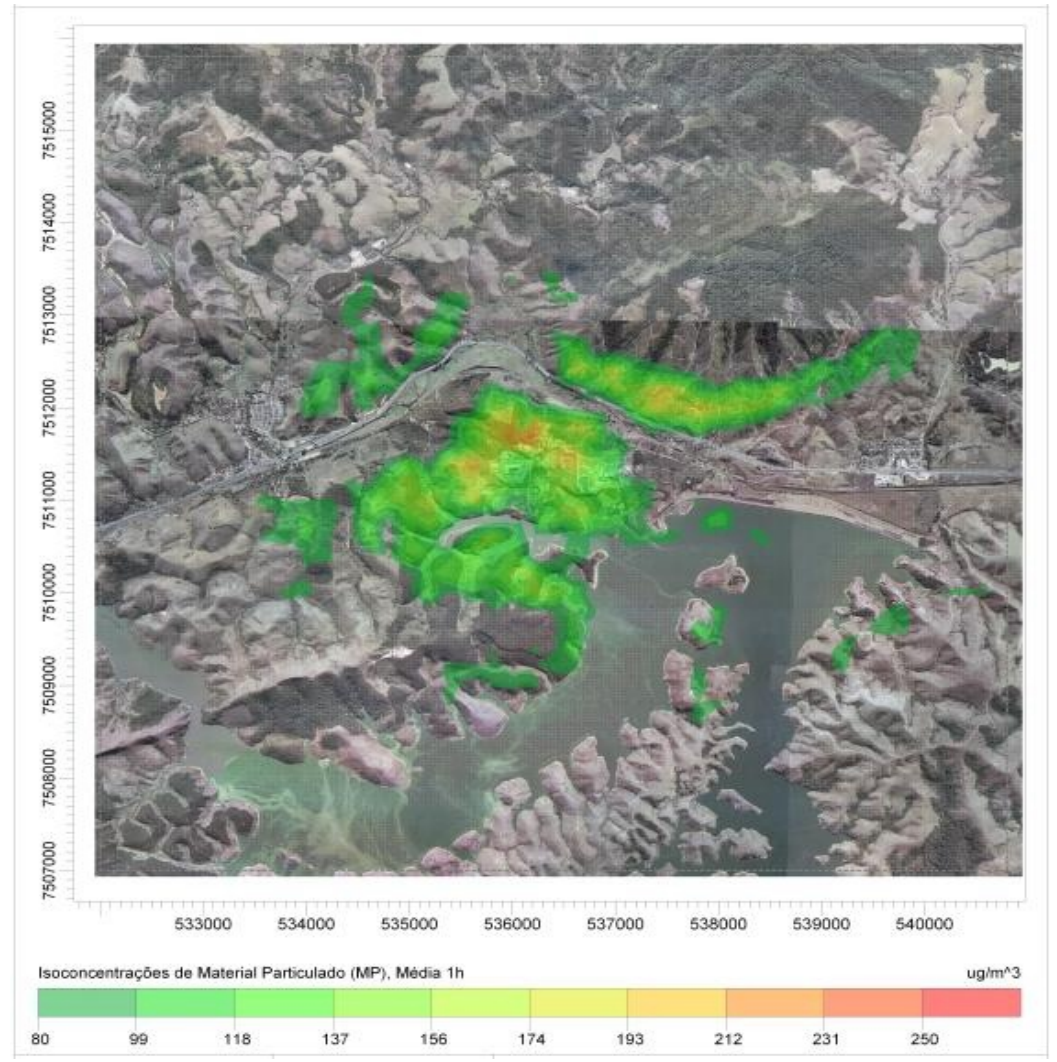

Figura 4 - Concentração Máxima de MP para as chaminés FPP e SS, 225,1 $\mu \mathrm{g} \mathrm{m}^{-3}$, Média 1 hora (sem edificações e com relevo)

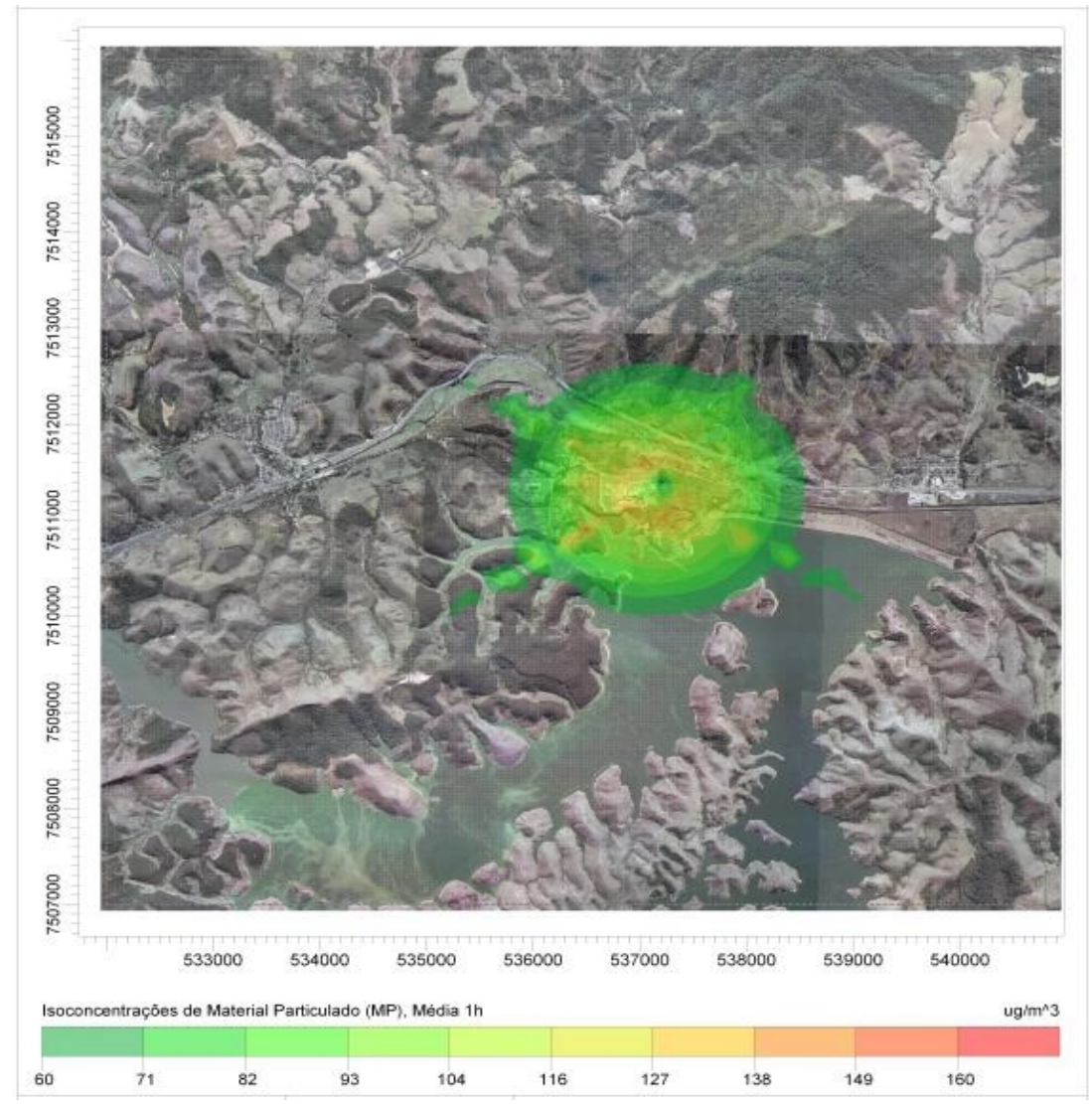

Figura 5 - Concentração Máxima de MP para as chaminés FPP e SS, 153,4 $\mu \mathrm{g} \mathrm{m}^{-3}$, Média 1 hora (sem edificações e sem relevo) 
Tabela 1 - Definição da Estabilidade Atmosférica segundo Pasquill-Gifford (Seinfeld e Pandis, 1998)

\begin{tabular}{ccccccc}
\hline $\begin{array}{c}\text { Velocidade do } \\
\text { vento }\end{array}$ & \multicolumn{4}{c}{ Radiação solar incidente } & \multicolumn{2}{c}{ Noite } \\
$\mathbf{m ~ s}^{-1}(\mathbf{a}$ 10 $\mathbf{~ m})$ & Forte & Moderada & Leve & $\begin{array}{c}\text { Levemente } \\
\text { Nublado } \geq \mathbf{4} / \mathbf{8}\end{array}$ & $\begin{array}{c}\text { Claro ou pouco } \\
\text { Nublado } \leq \mathbf{3 / 8}\end{array}$ \\
\hline 0 à 2 & $\mathrm{~A}$ & $\mathrm{~A}-\mathrm{B}$ & $\mathrm{B}$ & --- & -- \\
2 à 3 & $\mathrm{~A}-\mathrm{B}$ & $\mathrm{B}$ & $\mathrm{C}$ & $\mathrm{E}$ & $\mathrm{F}$ \\
3 à 5 & $\mathrm{~B}$ & $\mathrm{~B}-\mathrm{C}$ & $\mathrm{C}$ & $\mathrm{D}$ & $\mathrm{E}$ \\
5 à 6 & $\mathrm{C}$ & $\mathrm{C}-\mathrm{D}$ & $\mathrm{D}$ & $\mathrm{D}$ & $\mathrm{D}$ \\
$>6$ & $\mathrm{C}$ & $\mathrm{D}$ & $\mathrm{D}$ & $\mathrm{D}$ & $\mathrm{D}$ \\
\hline
\end{tabular}

\begin{tabular}{lll}
\hline Onde: & A: muito instável & D: neutra \\
& B: moderadamente instável & E: moderadamente estável \\
& C: levemente instável & F: muito estável
\end{tabular}

Tabela 2 - Dados de Entrada do Modelo ISCST3.

\begin{tabular}{|c|c|c|}
\hline LOCALIZAÇÃO DA FONTE E & \multicolumn{2}{|c|}{ CHAMINÉS } \\
\hline PARÂMETROS DE LIBERAÇÃO & Pó e Pastilha & Secador Spray \\
\hline Coordenada UTM X [m] & 536983,16 & 537159,84 \\
\hline Coordenada UTM Y [m] & 7511316,69 & 7511314,63 \\
\hline Altura de liberação dos gases [m] & 35 & 20 \\
\hline Taxa de emissão $[\mathrm{g} / \mathrm{s}]$ & 1,0 & 1,0 \\
\hline Temperatura de saída dos gases [K] & 292,1 & 323 \\
\hline Diâmetro interno da chaminé [m] & 1,6 & 0,48 \\
\hline Velocidade de saída dos gases [m/s] & 18,1 & 8,5 \\
\hline Vazão de saída dos gases $\left[\mathrm{m}^{3} / \mathrm{s}\right]$ & 36,39 & 1,54 \\
\hline \multicolumn{3}{|c|}{ Coordenadas da Torre Meteorológica em UTM } \\
\hline \multicolumn{3}{|l|}{ Zona: 23 (W 48 para W 42) (Sul) } \\
\hline Coordenada $X[\mathrm{~m}]$ & Coordenada $Y[\mathrm{~m}]$ & 7511464,40 \\
\hline \multirow{2}{*}{$1^{\circ}$ GRADE CARTESIANA } & \multicolumn{2}{|c|}{121 Receptores } \\
\hline & Eixo $X$ & Eixo $Y$ \\
\hline Coordenada SW [m] & 536000 & 7510800 \\
\hline Numero de pontos & 45 & 45 \\
\hline Espaco $[\mathrm{m}]$ & 200 & 200 \\
\hline Extensão [m] & 8800 & 8800 \\
\hline \multirow{2}{*}{$2^{\circ}$ GRADE CARTESIANA } & \multicolumn{2}{|c|}{2025 Receptores } \\
\hline & Fixo $x$ & Eixo $Y$ \\
\hline Coordenada SW [m] & 532000 & 7507000 \\
\hline Numero de pontos & 11 & 11 \\
\hline Espaco [m] & 100 & 100 \\
\hline Extensão [m] & 1000 & 1000 \\
\hline
\end{tabular}


Tabela 3 - Concentração Máxima de Material Particulado, Média de 1 hora - ISCST3

\begin{tabular}{|c|c|c|c|c|c|c|}
\hline Figuras & $\begin{array}{l}\text { Identificação } \\
\text { das Chaminés }\end{array}$ & $\begin{array}{c}\text { Concentração } \\
{\left[\mu \mathrm{g} \mathrm{m}^{-3}\right]}\end{array}$ & $\begin{array}{l}\text { *Localização } \\
\text { UTM x e y [m] }\end{array}$ & ${ }^{* *} \mathrm{Dis}$ & $\begin{array}{l}\text { ância } \\
\text { n] }\end{array}$ & Cenário \\
\hline Figura 2 & FFP e SS & 470,9 & 537000 e 7511200 & 128,5 & 184,0 & $\begin{array}{l}\text { Com relevo e com } \\
\text { prédios }\end{array}$ \\
\hline Figura 3 & FFP e SS & 537,7 & 537200 e 7511400 & 251,3 & 100,1 & $\begin{array}{l}\text { Sem relevo e com } \\
\text { prédios }\end{array}$ \\
\hline Figura 4 & FFP e SS & 225,1 & 536200 e 7511700 & 849,5 & 1012,4 & $\begin{array}{l}\text { Com relevo e sem } \\
\text { prédios }\end{array}$ \\
\hline Figura 5 & FFP e SS & 153,4 & 536500 e 7510900 & 625,3 & 764,9 & $\begin{array}{l}\text { Sem relevo e sem } \\
\text { prédios }\end{array}$ \\
\hline
\end{tabular}

Tabela 4 - Concentração Máxima de Material Particulado, Média de 1, 3, 12, 24 horas e Anual

\begin{tabular}{|c|c|c|c|c|c|}
\hline Período & $\begin{array}{l}\text { Identificação } \\
\text { das Chaminés }\end{array}$ & $\begin{array}{c}\text { Concentração } \\
{\left[\mu \mathrm{q} \mathrm{m} \mathrm{m}^{-3} \text {. }\right.}\end{array}$ & $\begin{array}{l}\text { Localização } \\
\text { UTM x e y [m] }\end{array}$ & $\begin{array}{l}\text { Distância } \\
{[\mathrm{m}]}\end{array}$ & Cenário \\
\hline 1 & \multirow{5}{*}{ FFP e SS } & 470,9 & 537000 e 7511200 & 128,5 e 184,0 & \multirow{5}{*}{$\begin{array}{l}\text { Com relevo e com } \\
\text { prédios }\end{array}$} \\
\hline 3 & & 236,0 & 536900 e 7511400 & 98,6 e 251,5 & \\
\hline 12 & & 96,1 & 536900 e 7511200 & 136.8 e 267.6 & \\
\hline 24 & & 72,5 & 536800 e 7511200 & 202,3 e 359,6 & \\
\hline Anual & & 16,4 & 537000 e 7511300 & 45,0 e 140,3 & \\
\hline
\end{tabular}

Tabela 5 - Comparação dos resultados obtidos com o ISCST3 e SCREEN (sem relevo e prédio)

\begin{tabular}{ccccc}
\hline \multirow{2}{*}{ Chaminé } & \multicolumn{2}{c}{ Conc. $\left(\mu \mathrm{g} \mathrm{m}^{-3}\right)$} & \multicolumn{2}{c}{ Distância $(\mathrm{m})$} \\
& ISCST3 & SCREEN & ISCST3 & SCREEN \\
\hline FPP & 16,7 & 19,0 & 1344,7 & 1340 \\
SS & 148,4 & 191,7 & 764,9 & 780 \\
\hline
\end{tabular}

